Int. J. Dev. Biol. 58: 563-573 (2014)

doi: $10.1387 / \mathrm{ijdb} .140084 \mathrm{ss}$

\title{
Expression of the wnt gene complement in a spiral-cleaving embryo and trochophore larva
}

\author{
MARGARET M. PRUITT"\#, EDWARD J. LETCHER, HSIEN-CHAO CHOU, BENJAMIN R. BASTIN \\ and STEPHAN Q. SCHNEIDER* \\ Department of Genetics, Development and Cell Biology, lowa State University, Ames, IA, USA
}

\begin{abstract}
The highly conserved wnt gene family has roles in developmental processes ranging from axis formation to cell fate determination. The polychaete Platynereis dumerilii has retained 12 of the 13 ancient wnt subfamilies and is a good model system to study the roles of the wnt ligands in spiralian development. While it has been shown that Platynereis uses a global $\beta$-cateninmediated binary cell fate specification module in development, the early roles of the 12 wnt genes present in Platynereis are unknown. Transcriptional profiling by RNA-Seq during early development and whole-mount in situ hybridization of embryo and larval stages were used to determine the temporal and spatial regulation of the wnt complement in Platynereis. None of the 12 wnt transcripts were maternally provided at significant levels. In pregastrula embryos, zygotic wntA, wnt4, and wnt5 transcripts exhibited distinctive patterns of differential gene expression. In contrast, in trochophore larvae, all 12 wnt ligands were expressed and each had a distinct expression pattern. While three wnt ligands were expressed in early development, none were expressed in the right place for a widespread role in $\beta$-catenin-mediated binary specification in early Platynereis development. However, the expression patterns of the wnt ligands suggest the presence of numerous wnt signaling centers, with the most prominent being a bias for staggered posterior wnt expression in trochophore larvae. The similarity to wnt expression domains in cnidarians around the blastopore and the tail organizer in chordates supports a hypothesis of a common evolutionary origin of posterior organizing centers.
\end{abstract}

KEY WORDS: wnt, spiral cleaving, signaling center, trochophore, polychaete

Wnts are secreted, lipid-modified proteins that are thought to act as morphogens and travel to a receiving cell. There are a number of Wnt receptors, and the binding of a Wnt ligand to a receptor will trigger a variety of intracellular responses. The consequence of a Wnt signal is an activated transcriptional program that will give rise to a biological response, such as cell proliferation, cell fate determination, or axis formation (Logan and Nusse, 2004). The response to a Wnt signal and activated transcription is dependent on the cellular context, as Wnt signaling is involved in many processes from development to adult tissue homeostasis. There are three main pathways that are activated by secreted Wnt proteins: the canonical Wnt/ $\beta$-catenin pathway, the noncanonical planar cell polarity (PCP) pathway, and the $\mathrm{Wnt} / \mathrm{Ca}^{2+}$ pathway. The Wnt/ $\beta$-catenin signaling pathway is highly conserved in metazoans and has two states;
OFF that causes the degradation of cytoplasmic $\beta$-catenin, and ON that occurs when Wnt ligands bind to the receptors Frizzled and LRP5/6, and triggers an intracellular signaling cascade ending with the transcription of Wnt target genes. The interaction of the Wnt ligand with its receptors will block the antagonistic activity of GSK3 $\beta$ that normally targets cytoplasmic $\beta$-catenin for degradation (Logan and Nusse, 2004).

Wntgene diversity is ancient, as phylogenomic analyses suggest the presence of thirteen wht genes present in the last common ancestor between the diploblastic cnidarians and bilaterally symmetric animals (Cho et al., 2010; Janssen et al., 2010; Kusserow

Abbreviations used in this paper: hpf, hours post fertilization; WMISH, whole-mount in situ hybridization.

*Address correspondence to: Stephan Q. Schneider. Genetics, Development and Cell Biology, 503 Science Hall II, lowa State University, Ames, IA 50011, USA.
Tel: +1-515-294-4956. Fax: +1-515-294-8457. E-mail: sqs @ iastate.edu

\#Current address: Department of Pediatrics, University of Chicago, Chicago, IL, USA.

Supplementary Material for this paper is available at: http://dx.doi.org/10.1387/ijdb.140084ss

Accepted: 20 June 2014

ISSN: Online 1696-3547, Print 0214-6282

(C) 2014 UBC Press

Printed in Spain 
et al., 2005). Significantly, this ancestral gene set has been largely retained by some animals, such as the cnidarian sea anemone Nematostella vectensis (Kusserow et al., 2005; Lee et al., 2006), several protostomes like the crustacean Daphnia pulex (Janssen et al., 2010), the mollusk Lottia gigantea (Cho et al., 2010), the annelids Platynereis dumerilii (Janssen et al., 2010) and Capitella teleta (Cho et al., 2010), and the deuterostome chordate Branchiostoma floridae (Croce et al., 2006; Holland, 2002) and echinoderm Strongylocentrotus purpuratus (Croce et al., 2006). In other animal lineages, the ancestral wnt gene complement has been modified with gene loss, dramatically seen in the ecdysozoan nematodes like Caenorhabditis elegans and the arthropod Drosophila melanogaster (Janssen et al., 2010; Ruvkun and Hobert, 1998), or gene duplication, like in Xenopus tropicalis, Danio rerio, and Homo sapiens (Garriock et al., 2007).

Platynereis dumerilii has retained 12 of the 13 ancient wnt genes lacking wnt3only. Thus, the wnt complement in Platynereis is well conserved and provides an opportunity to study individual wnt gene function in a species untainted by compensatory mechanisms occurring after wnt gene loss or gain as observed in other animal lineages. Platynereis dumerilii is a marine polychaete annelid and a member of the superphylum Lophotrochozoa. In early development, Platynereis embryos first exhibit a spiral cleavage pattern before transitioning into a pattern of bilaterally symmetric cell divisions (Fig. 1). The spiral cleavage pattern is invariant and unequal in Platynereis (Fig.1) (Dorresteijn, 1990; Fischer and Dorresteijn, 2004; Fischer et al., 2010), with the first two cell divisions producing four cells of unequal size, named $A, B, C$, and $D$, that define the quadrants of the embryonic cell lineage. The third round of cell divisions creates the micromeres (1a, 1b, 1c, $1 \mathrm{~d})$ that are located at the animal pole, and macromeres $(1 \mathrm{~A}, 1 \mathrm{~B}$, $1 \mathrm{C}, 1 \mathrm{D})$ located at the vegetal pole. The first micromeres (1a-1d) are located slightly to the left of the vegetal sister macromeres
(1A-1D). The orientation of the sister cells with respect to one another alternates with the next round of cell divisions $\left(1 \mathrm{a}^{1}\right.$ is located slightly to the right of $1 \mathrm{a}^{2}$ ), and continue to alternate with each division, creating a spiral pattern. This stereotyped, unequal cleavage pattern enables individual cells to be identified by size and position, and has allowed the complete cell lineage of early Platynereis embryos to be determined up to the $\sim 220$ cell stage (Schneider and Bowerman, 2007). Platynereis embryos transition from a spiral cleavage pattern to a bilaterally symmetric cleavage pattern when two cells, $4 \mathrm{~d}$ and $2 \mathrm{~d}^{112}$, progenitor cells for trunk mesoderm and ectoderm, respectively, divide equally (Fig.1). These two cells divide perpendicular to the animal-vegetal axis and are important to establish the bilateral symmetry in the trunk of larvae and adult worms.

In later development, Platynereis has a larval phase with a few notable features (Fig.1). Early (24hpf) and late (48hpf) trochophore larvae have three ciliated regions in common: the apical organ at the anterior pole, the equatorial prototroch, and the telotroch near the posterior. Also common between $24 \mathrm{hpf}$ and $48 \mathrm{hpf}$ larvae is the presence of the stomodeum on the ventral side and developing chaetal sacs (primordial appendages) laterally (Fischer and Dorresteijn, 2004; Fischer et al., 2010). The posterior end at 24hpf is the proctodeal region that will later give rise to the proctodeum and pygidium by $48 \mathrm{hpf}$. In the 48hpf larva, three appendage bearing larval segments $(1,2$, and 3 ) have formed in the trunk region. Also shown in the $48 \mathrm{hpf}$ larva (Fig.1C) is a territory called the peristomium, a larval region described here as posterior to the prototroch, but anterior to the first segment, and contains the stomodeum.

Previous studies have revealed potential wnt-related mechanisms in embryos and larvae of annelids. During early Platynereis development, the $\beta$-catenin signaling pathway functions in a reiterative binary mode to specify cell fates (Schneider and Bowerman,
A

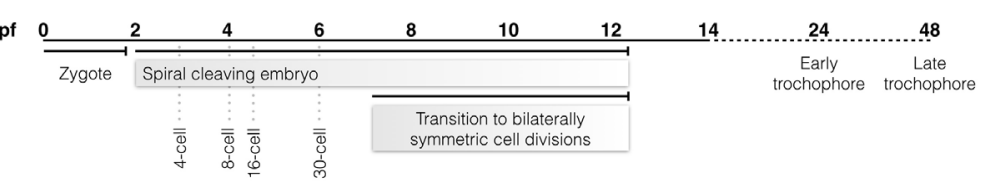

B

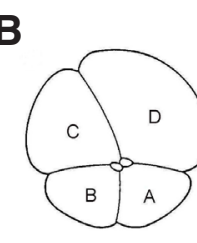

4-cell

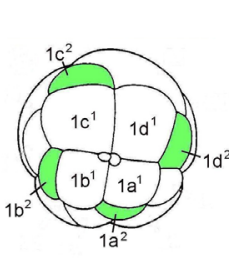

16-cell

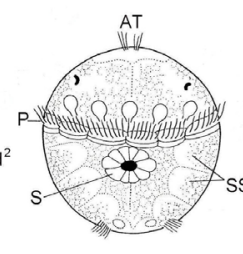

Early trochophore

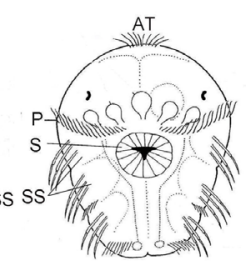

Late trochophore
C

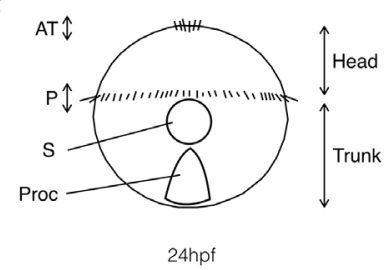

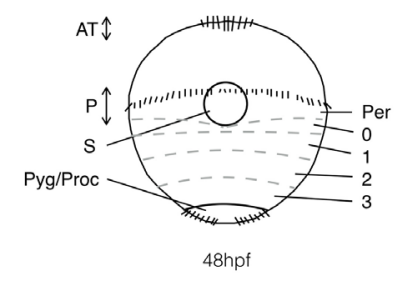

Fig. 1. Platynereis dumerilii development. (A) Timeline of Platynereis development from fertilization (Ohpf) to early and late trochophore larvae (24hpf and 48hpf). Platynereis embryos exhibit a spiral pattern of cleavages early on, and then transition to a more bilaterally symmetric pattern of cell divisions after 7 hpf. (B) Schematics are modified from Fischer and Dorresteijn, 2004. 4-, 8-, and 16-cell stage schematics are animal pole views, while the early and late trochophore schematics are ventral views with the anterior to the top. The 4-16-cell schematics show the unequal spiral cleavage pattern seen in Platynereis embryos, as well as the nomenclature of the four embryonic quadrants, $A, B, C$, and $D$. The two, small circles at the animal pole in the 4-, 8-, and 16-cell stage schematics represent polar bodies. (C) Additional schematics of the trochophore larvae (24hpf and 48hpf) showing structures and areas that were used to describe expression patterns. These are ventral views with the anterior to the top. Abbreviations in the trochophore larvae: AT, apical tuft (apical organ); P, prototroch; $S$, stomodeum; SS, setal (chaetal) sacs; Proc, proctodeal region; Pyg/Proc, pygidium/proctodeum; Per, peristomium, 0, transient larval segment; and 1-3, larval segments 1-3. The head region/episphere gives rise to the apical organ, eyes, and brain, and is located anterior to the prototroch. The prototroch is a ciliated ring around the larva. The trunk region/hyposphere is located posterior to the prototroch (and posterior to the peristomium in 48hpf), and contains the chaetal sacs, the larval segments, and the pygidium/proctodeum. Larval segments are named as they are in Janssen et al., 2010. 
2007). The binary specification module mediated by $\beta$-catenin in Platynereis operates between sister cells whenever an embryonic cell division occurs along the animal-vegetal axis. Those sister cells that were located more towards the vegetal pole exhibited high levels of $\beta$-catenin protein, while the animal pole sister cells exhibited low levels of $\beta$-catenin throughout early development. When $\beta$-catenin was ectopically activated through the use of a GSK3 $\beta$ inhibitor, those animal pole sister cells that usually exhibited low levels of $\beta$-catenin accumulated high levels of $\beta$-catenin. This accumulation of $\beta$-catenin caused the animal pole sister cells to adopt the cell fate of the vegetal pole sister cells. Therefore, reiterative ON and OFF states of $\beta$-catenin signaling must play an instructive role for determining cell fates during early development in a binary manner (Schneider and Bowerman, 2007). Whether or not Wnt ligands are involved in the $\beta$-catenin-mediated binary cell fate specification in Platynereis is unknown. Although studied in several animal embryos, it is currently not understood how the complement of ancient wnt subfamilies is utilized to pattern spiral-cleaving embryos. Cho and colleagues have studied the wnt complement in the leech Helobdella robusta, a spiral-cleaving and direct developing annelid (Cho et al., 2010), and this is the only other publication to date that has studied the wnt complement in early development in any spiralian model system. Studies on later roles for wnt ligands in Platynereis have focused on segmentation (Janssen et al., 2010), and annelid brain development in trochophore larva (Tomer et al., 2010). The expression of wnt genes has also been studied in later development of Helobdella and Capitella, more derived annelids that skip or shorten the trochophore larval stages (Cho et al., 2010).

To identify potential wnt signaling centers in spiral-cleaving embryos and early and late trochophore larvae, the expression of all 12 wnt genes in Platynereis was studied. Transcriptional profiling by RNA-Seq and whole-mount in situ hybridization (WMISH) were used to determine the temporal and spatial regulation of wnt genes in the early cleavage stages. RNA-Seq results suggest that only a small subset of wnts is expressed in early development. WMISH further shows that each of these wnts exhibits a distinct cellular pattern of gene expression that can be traced back to individual cells. Surprisingly, none of the 12 wnt ligands appears to be expressed in the right place and the right time to be a good candidate to orchestrate the global $\beta$-catenin-mediated binary cell fate specification module in early Platynereis development. In contrast to early embryos, all 12 wnt genes are expressed in distinct patterns in early and late trochophore larvae, suggesting the presence of numerous potential wnt signaling centers. Of particular interest is a strong bias for staggered posterior expression of the wnt genes in the trochophore reminiscent of similar biased expression domains in cnidarians centered at the blastopore, and the tail organizer in chordate embryos. These similarities support the hypothesis of a common evolutionary origin of posterior organizing centers in bilaterians, and blastoporal signaling centers in cnidarians.

\section{Results}

\section{Temporal gene expression of the wnt complement during early development}

To establish the expression levels for each of the 12 wntgenes over the course of early development, transcriptional profiles were generated from the one-cell stage (2 hours post fertilization, $2 \mathrm{hpf}$ ) to the $\sim 330$-cell stage (14hpf) in Platynereis (compare to Fig. 1). To do so the transcriptome in early Platynereis embryos was determined by deep sequencing of RNA isolated in 2-hour intervals starting with the zygote (2hpf), early spiral cleavage stages (4hpf, $6 \mathrm{hpf}$ ), the transition to bilateral symmetry (8hpf, 10hpf), and gastrula stages (12hpf, 14hpf) (Chou, Bastin, and Schneider, unpublished data). Transcriptome analysis revealed that 4 of the 12 wnt ligands, wnt4, wnt5 (the alternative splice forms wnt5a and wnt5b), wnt8, and $w n t A$, are expressed at significant levels in early Platynereis development (Fig. 2). Of particular interest is that only 3 of the 12 wnt ligands encoded by the Platynereis genome are expressed in early Platynereis embryos and each wnt has an overlapping, yet distinct, temporal pattern of gene expression. Even more

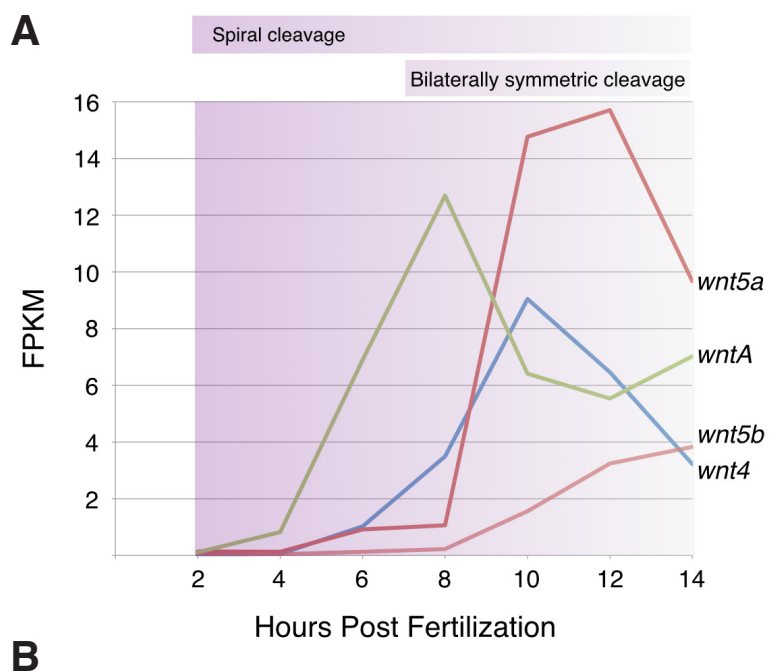

\begin{tabular}{|c|c|c|c|c|c|c|c|}
\hline Gene & $2 \mathrm{hpf}$ & $4 \mathrm{hpf}$ & $6 h p f$ & 8hpf & 10hpf & $12 \mathrm{hpf}$ & $14 \mathrm{hpf}$ \\
\hline wnt1 & 0.0 & 0.0 & 0.0 & 0.0 & 0.0 & 0.0 & 0.0 \\
\hline wnt2 & 0.0 & 0.0 & 0.1 & 0.1 & 0.1 & 0.0 & 0.0 \\
\hline wnt4 & 0.0 & 0.1 & 1.0 & 3.5 & 9.0 & 6.5 & 3.2 \\
\hline wnt5a* & 0.1 & 0.1 & 0.9 & 1.1 & 14.8 & 15.7 & 9.7 \\
\hline$w n t 5 b^{*}$ & 0.1 & 0.0 & 0.1 & 0.2 & 1.6 & 3.2 & 3.8 \\
\hline wnt6 & 0.0 & 0.0 & 0.0 & 0.1 & 0.1 & 0.1 & 0.0 \\
\hline wnt7 & 0.0 & 0.0 & 0.2 & 0.1 & 0.1 & 0.1 & 0.0 \\
\hline wnt8 & 0.3 & 0.5 & 1.0 & 0.9 & 3.5 & 2.9 & 2.5 \\
\hline wnt9 & 0.0 & 0.0 & 0.0 & 0.1 & 0.2 & 0.1 & 0.1 \\
\hline$w n t 10$ & 0.1 & 0.0 & 0.0 & 0.0 & 0.0 & 0.0 & 0.1 \\
\hline$w n t 11$ & 0.0 & 0.0 & 0.0 & 0.1 & 0.1 & 0.9 & 2.3 \\
\hline wnt16 & 0.1 & 0.0 & 0.0 & 0.1 & 0.2 & 0.1 & 0.2 \\
\hline$w n t A$ & 0.1 & 0.8 & 6.9 & 12.7 & 6.4 & 5.5 & 7.0 \\
\hline
\end{tabular}

Fig. 2. wnt gene expression during early Platynereis development based on stage-specific transcriptional profiling during the first $14 \mathrm{~h}$ of development. (A) The plot illustrates the relative expression levels of wntA, wnt4, and wnt5 in FPKM (fragments per kilobase per million mapped reads). Each wnt has a distinct temporal pattern of gene expression. wntA expression peaks at 8hpf, wnt4 peaks at 10hpf, and wnt5a expression peaks at $12 \mathrm{hpf}$. (B) The table displays the relative expression levels of each of the 12 wnt genes found in the genome of Platynereis in median FPKM values from two biological replicates for each stage (see Sup. Table 1). The values suggest wntA, wnt4, wnt5, and wnt8 are expressed at significant levels in the early Platynereis embryo. Asterisk by wnt5a and wnt5b denotes that these are two splice forms of a single wnt5 gene. 
intriguing are the lack of significant maternal contribution by any wnt gene, and the relatively late onset of some wnt gene expression during the transition from a spiral to bilateral symmetrically cleaving embryo (between 6hpf and 8hpf). The RNA-sequencing data revealed that wnt8 has a slight maternal contribution, but in general, there is no major maternal contribution by the wnt genes.

\section{Spatial gene expression in early development}

Spatial gene expression of the wnt gene complement was characterized at selected stages of Platynereis development guided by the quantitative transcriptional data. Initially, the expression for all twelve wnt ligands was determined with WMISH at $12 \mathrm{hpf}$ to validate the RNA-sequencing results. Only wntA, wnt4, wnt5, and $w n t 8$ are expressed at detectable levels at $12 \mathrm{hpf}$, while none of the other eight wnt genes exhibit any visible expression (Fig. 3-5, Supplementary Fig. 1, and data not shown). All twelve wnt genes yielded distinct differential expression patterns by WMISH in later larval stages (Fig. 6, Supplementary Figs. 2,3). Thus, absence

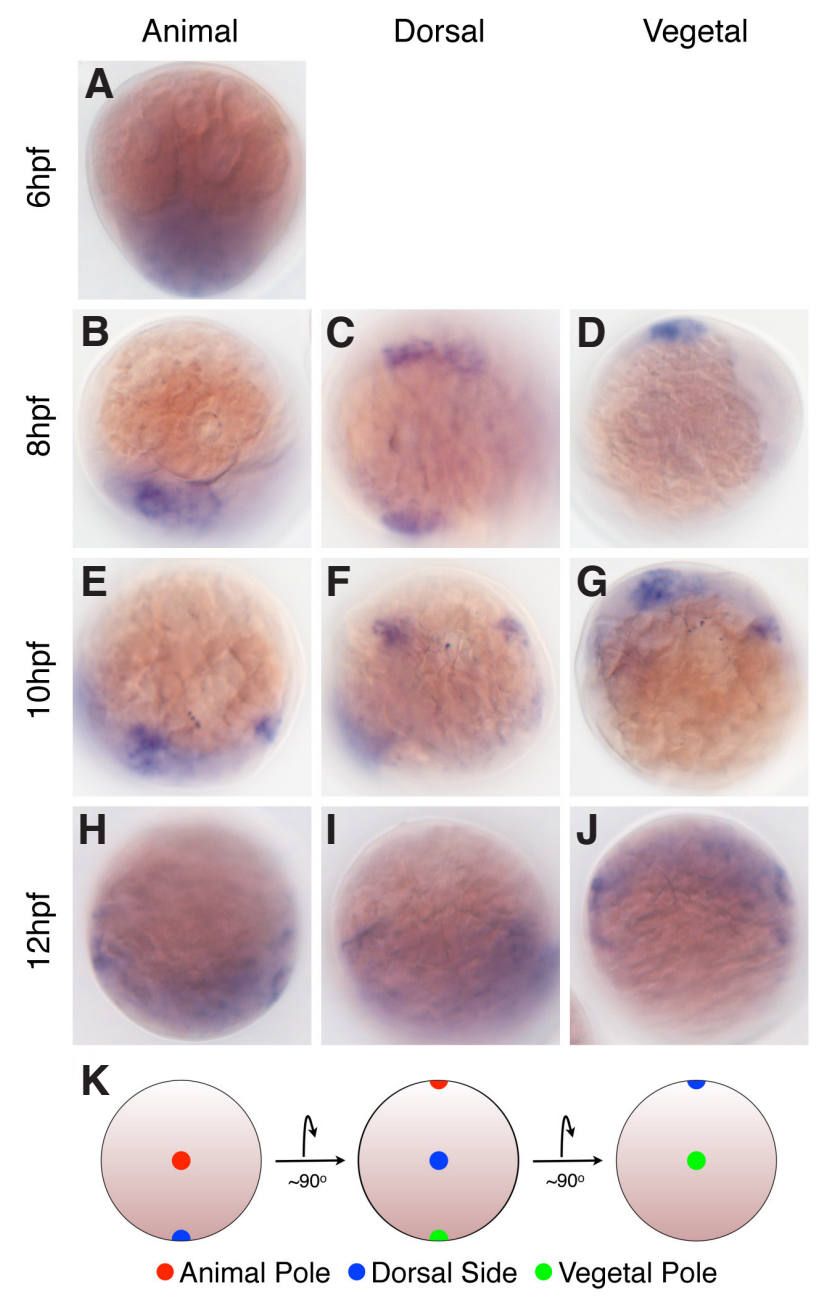

Fig. 3. Spatial gene expression of wntA during early development. WMISH of wntA on (A) 6hpf, (B-D) 8hpf, (E-G) 10hpf, and (H-J) 12hpf embryos. (A), (B), (E), and (H) are animal pole views with the dorsal side down, (C), (F), and (I) are dorsal views with the animal pole up, and (D), $\mathbf{( G )}$, and $\mathbf{( J )}$ are vegetal pole views with the dorsal side up. (K) Schematic of the orientation of (A-J) with respect to one another. of early expression of the eight wnt genes is not due to technical problems with WMISH and confirms the quantitative developmental transcriptional data.

Of the twelve wnt ligands present in Platynereis, wntA has the earliest expression determined by WMISH. At 6hpf, wntA is expressed in only one cell, $2 d^{1}$ (Fig. $3 A$ ). The cell $2 d^{1}$ is a descendant of the first somatoblast, $2 \mathrm{~d}$, which is the sole progenitor of trunk ectoderm including the neuroectoderm that will form the ventral nerve cord. The expression domain of $w n t A$ increases during the next two hours of development from one cell to 9-12 cells at $10 \mathrm{hpf}$ (Fig. $3 \mathrm{~B}-\mathrm{G}$ ) consistent with a series of fast cell divisions of $2 \mathrm{~d}^{1}$. Thus, wntAtranscripts are found in patches around nuclei in cells on the dorsal side of the embryo spread out along the animal-vegetal axis. As development continues, $w n t A$ is more evenly distributed within cells in a broader area, covering most of the dorsal side of the embryo (Fig. 3 H-J, Fig. 7).

wnt4 is the next wnt ligand in Platynereis where early expression is detected. Transcriptional profiling data shows an increase in wnt4 expression between 6hpf and $8 \mathrm{hpf}$ (Fig. 2). However, the earliest wnt4 expression detected by WMISH is at 8hpf (Fig. 4). At 8hpf, wnt4 is expressed in 5-6 cells in the $C$ and $D$ lineages, and by $12 \mathrm{hpf}$ there are 7-9 cells with wnt 4 expression. The most anterior expression of wnt4 at $8 \mathrm{hpf}$ is in two lateral patches of cells, just below the most apical region, and likely the descendants of $1 c^{112}$ and $1 \mathrm{~d}^{112}$. Additional individual wnt4 expressing cells are located along the dorsal midline (Fig. 4 C, F). Similarly to $w n t A$, the expression of wnt4 is found on the dorsal side of the embryo based on patterns of DAPI stained nuclei (data not shown). However, wnt4 is expressed in specific subsets of dorsal cells, mostly not overlapping with dorsal $w n t A$ expressing cells, and is not expressed throughout the entire dorsal side of the embryo (compare wnt4 and $w n t A$ in Fig. 7).

$w n t 5$ is the last of the wnt ligands present in Platynereis with a detectable expression pattern within the first 12 hours of development. wnt5a is expressed in $\sim 4$ cells at 8 hpf (Fig. $5 \mathrm{~A}-\mathrm{C}$ ), and 8 to 9 cells by $12 \mathrm{hpf}$ (Fig. $5 \mathrm{G}-\mathrm{I})$. At $8 \mathrm{hpf}$ and $10 \mathrm{hpf}$, three of the wnt5a expressing cells are along the dorsal midline (Fig. 5 B,E). At 12hpf, wnt5a is expressed in two cells in the anterior half of the embryo, located bilaterally across from one another (Fig. $5 \mathrm{G}, \mathrm{H}$ ), and in a number of cells at the posterior/vegetal pole.

While the transcriptome analysis suggests that wnt8 is also expressed during early development in Platynereis, a specific expression pattern could not be detected with WMISH (Supplementary Fig. 1). There was no expression of wnt8 at $8 \mathrm{hpf}$ or $10 \mathrm{hpf}$, and the expression at $12 \mathrm{hpf}$ was ubiquitous and just at the detection level.

\section{Spatial expression in early (24 hpf) and late (48hpf) trocho- phore larvae}

To determine potential wnt signaling centers in trochophore larvae of Platynereis, the expression of the twelve wnt ligands was determined at $24 \mathrm{hpf}$ and $48 \mathrm{hpf}$. Whereas the expression of the wnt complement in early trochophore larvae (24hpf) has not been reported yet, two previous publications described patterns of wht expression in late trochophore larvae (48hpf) with a focus on segmentation (Janssen et al., 2010) and brain development (Tomer et al., 2010). In general, the wnt gene expressions at 48hpf reported here confirm most of the previously established expression pattern for the wnt ligands during larval segmentation and within the developing brain. However, the expression domains for 

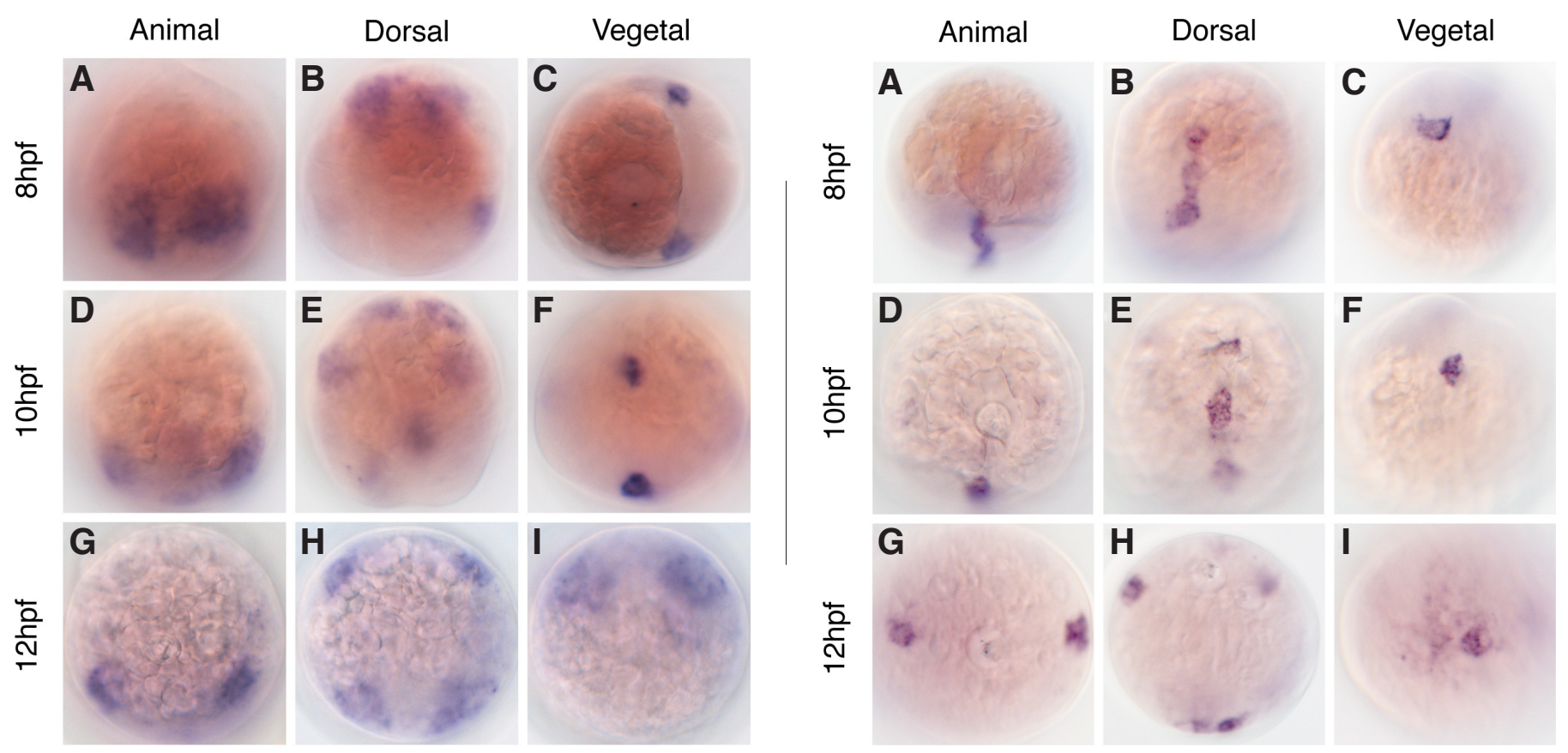

Fig. 4 (Left). Spatial gene expression of wnt4 during early development. WMISH of wnt4 on (A-C) 8hpf, (D-F) 10hpf, and (G-I) 12hpf embryos. (A), $(\mathbf{D})$, and $(\mathbf{G})$ are animal pole views with the dorsal side down, (B), (E), and $\mathbf{( H )}$ are dorsal views with the animal pole up, and (C), (F), and (I) are vegetal pole views with the dorsal side up. Compare to Fig. 3 K for embryo orientation.

Fig. 5 (Right). Spatial gene expression of wnt5a during early development. WMISH of wnt5a on (A-C) 8hpf, (D-F) 10hpf, and (G-I) 12hpf embryos. (A), (D), and (G) are animal pole views with the dorsal side down, (B), (E), and (H) are dorsal views with the animal pole up, and (C), (F), and (I) are vegetal pole views with the dorsal side up. Compare to Figure $3 \mathrm{~K}$ for embryo orientation.

several wnt ligands were missing, and some of the patterns seen at 48hpf shown here are different.

Each wht ligand has a distinct pattern of expression in trochophore larvae, and while there are similarities between the wnts none of the expression patterns are the same. However, while the expression patterns are different, in many cases there are multiple wnt ligands expressed in the same larval region. wnt2, wnt4, wnt5, $w n t 8, w n t 11$, and $w n t A$ are all expressed in the developing brain anterior to the prototroch (Fig. 1C, Fig. 6, Supplementary Figs. 2,3). Each of these wnt ligands has a distinct expression pattern, but the expression patterns also have a high degree of overlap. The larval regions with the most overlap of wnt ligand expression are the trunk ectoderm and trunk mesoderm. At $24 \mathrm{hpf}, 10$ of the 12 wnt ligands are expressed in either the trunk ectoderm or trunk mesoderm (wnt1, wnt4, wnt5, wnt6, wnt7, wnt8, wnt10, wnt11, $w n t 16$, and $w n t A)$. There are 9 of the $12 w n t$ ligands expressed in these regions at 48hpf (wnt1, wnt4, wnt5, wnt7, wnt8, wnt10, wnt11, wnt16, and wntA). Interestingly, the three wnt ligands not expressed in the trunk ectoderm or trunk mesoderm at $48 \mathrm{hpf}$ are expressed in a region more posterior, the pygidium/proctodeum (wnt2, wnt6, and wnt9). Similarly, one of the two wnt ligands, $w n t 9$, not expressed in the trunk ectoderm or trunk mesoderm is expressed in the proctodeal region at $24 \mathrm{hpf}$. The only wnt ligand not expressed in the posterior of the Platynereis larva at $24 \mathrm{hpf}$ is wnt2, which is expressed just anterior to the prototroch. From this data, there appears to be a strong bias for wnt ligands to be expressed in the posterior, in contrast to a selective expression of a few wnt ligands in the anterior.

Wnt1: At $24 \mathrm{hpf}$, wnt1 is weakly expressed in the truck ectoderm and strongly in two areas in the proctodeal region (Fig. 6A and Supplementary Fig. 2). The expression of $w n t 1$ is expanded and elevated by $48 \mathrm{hpf}$. At $48 \mathrm{hpf}$, wnt1 is expressed in the trunk ectoderm in the posterior half of segments 1,2 , and 3 as well as the pygidium/proctodeum (Fig. 6G). wnt1 also has slight expression in the developing brain at 48hpf (Supplementary Fig. 3).

Wnt2: wnt2 is expressed in two small symmetrical areas anterior to the prototroch at $24 \mathrm{hpf}$ (Fig. 6B). By $48 \mathrm{hpf}$, wnt2 is expressed in parts of the developing larval brain, and in the pygidium/proctodeum area (Fig. $6 \mathrm{H}$ and Supplementary Fig. 3). This is the first reported analysis of wnt2 expression pattern in early and late trochophore larvae, and was missed by Tomer and colleagues (Tomer et al., 2010) in the screen for wnt genes expressed in Platynereis brain regions.

Wnt4: wnt4 is expressed in the trunk ectoderm and in two symmetrical areas in the developing brain at 24hpf (Fig. 6C and Supplementary Fig. 2). By 48hpf, wnt4 is expressed in the stomodeum, anterior half of segments 1, 2, and 3 in the trunk ectoderm, and along the ventral midline along segments 1, 2, and 3 (Fig. $6 \mathrm{l}$ and Supplementary Fig. 3).

Wnt5: wnt5 is expressed in two bilaterally symmetric regions in the developing larval brain at $24 \mathrm{hpf}$, as well as in a segmented-like pattern in the trunk ectoderm and mesoderm, and strongly in the proctodeal region (Fig. 6D and Supplementary Fig. 2). At 48hpf, $w n t 5$ has the most anterior expression of all of the wnt ligands. wnt5 is expressed in the developing brain, the peristomium, the stomodeum and the anterior half of segments 1,2 , and 3 in the trunk ectoderm and mesoderm (Fig. 6J and Supplementary Fig. $3)$. The brain expression for wnt5 at $48 \mathrm{hpf}$ is similar to the pattern 
shown in Tomer et al., (Tomer et al., 2010).

Wnt6: wnt6 has a weak expression pattern at $24 \mathrm{hpf}$ and $48 \mathrm{hpf}$. At $24 \mathrm{hpf}, w n t 6$ is faintly expressed in the proctodeal region and surrounding mesoderm (Fig. 6E and Supplementary Fig. 2). wnt6 expression becomes localized to the pygidium/proctodeum at 48hpf (Fig. 6K and Supplementary Fig. 3). The expression pattern shown for wnt6 by Janssen and colleagues is a broad mesodermal expression domain in the trunk (Janssen et al., 2010). The difference in expression pattern from Janssen and colleagues and the pattern shown here could be due to different regions of wnt6 used for RNA probe synthesis.

Wnt7:At 24hpf, wnt7 is expressed in the mesoderm in two small, symmetrical areas posterior to the prototroch in the peristomium. wnt7 is also expressed slightly in the trunk mesoderm at 24hpf (Fig. 6F and Supplementary Fig. 2). At 48hpf, wnt7 continues to be expressed in the peristomium and the segmental mesoderm (Fig. 6L and Supplementary Fig. 3). The peristomium expression of wnt7 at 48hpf was not described previously (Janssen et al., 2010).

Wnt8: wnt8 is expressed in the developing brain and two additional bands, both anterior and posterior to the prototroch at $24 \mathrm{hpf}$ (Fig. 6M and Supplementary Fig. 2). wnt8 is also expressed in the trunk mesoderm at $24 \mathrm{hpf}$. At $48 \mathrm{hpf}$, wnt8 is strongly expressed in the developing brain, the peristomium, and in short ectodermal stripes in trunk segments 1, 2, and 3 (Fig. 6S and Supplementary Fig. 3). Similar to wnt5, the expression of wnt8 in the developing brain at 48hpf is in agreement with Tomer et al., (Tomer et al., 2010).

Wnt9: wnt9 has a small but specific region of expression at $24 \mathrm{hpf}$ and 48hpf. At both times in development, wnt9 is expressed in the proctodeum (Fig. 6N, T, Supplementary Figs. 2,3).

Wnt10: At 24hpf, wnt10 has slight expression in the trunk mesoderm and ectoderm, and in the proctodeal region (Fig. 60 and Supplementary Fig. 2). At 48hpf, wnt10 is expressed in the peristomium, the trunk ectoderm in the posterior half of segments 1,2 , and 3 , and the pygidium/proctodeum (Fig. 6U and Supplementary Fig. 3). The expression pattern for wnt10 shown here at 48hpf is more extensive than what was previously shown (Janssen et al., 2010).

Wnt11: wnt11 has the most anterior expression of all Platynereis wnt ligands at $24 \mathrm{hpf}$. At $24 \mathrm{hpf}$, wnt11 is also expressed in the stomodeum, the ventral midline, the trunk ectoderm and mesoderm, and proctodeal region (Fig. 6P and Supplementary Fig. 2). The expression of wnt11 strengthens at $48 \mathrm{hpf}$, and is expressed in the developing larval brain, the peristomium, the stomodeum, the posterior half of segments 1, 2, and 3 in the trunk

Fig. 6. Expression of the wnt gene complement in early (24hpf) and late (48hpf) trochophore larvae. Both in situ images and schematics are ventral views with the anterior of the specimen up. Gene expression analysis was performed withWMISH, and the neighboring schematic represents the expression pattern as a projection of all focal planes of the larva. Rows 1, 3, 5, and 7 are early trochophore larvae (24hpf), and rows 2 , 4,6 , and 8 are late trochophore larvae (48hpf). Refer to the text for details on the expression patterns as well as Sup. Fig. 2 and Sup. Fig. 3. 
ectoderm and mesoderm, the pygidium/proctodeum (Fig. 6V and Supplementary Fig. 3).

Wnt16:At 24hpf, wnt16 is expressed in two symmetrical areas in the trunk ectoderm (Fig. 6Q and Supplementary Fig. 2). By 48hpf, wnt16 expression has strongly increased. wnt16 is expressed in the peristomium, a transient segment posterior to the peristomium, the posterior half of segments 1, 2, and 3 in the trunk ectoderm, and the pygidium/proctodeum (Fig. 6W and Supplementary Fig. 3).

WntA: The most anterior expression of $w n t A$ at $24 \mathrm{hpf}$ is in the developing brain (Supplementary Fig. 2). At 24hpf, wntA is also expressed posterior to the prototroch in the peristomium, and weakly in the trunk ectoderm (Fig. 6R). At 48hpf, wntA is expressed in the developing larval brain, the peristomium, the stomodeum and the parapodial primordia (Fig. 6X and Supplementary Fig. 3).

\section{Discussion}

\section{Do Wnt ligands trigger $\beta$-catenin-mediated binary cell fate specification?}

Extensive reiterative asymmetric $\beta$-catenin localization patterns have been observed between sister cells in early embryos of Platynereis dumerilii after every embryonic cell division that occurs along the animal-vegetal axis. The animal pole sister cell has lower levels of nuclear $\beta$-catenin while the vegetal pole sister cell has high levels of nuclear $\beta$-catenin. Ectopic activation of $\beta$-catenin causes the animal pole sister cell to accumulate high levels of nuclear $\beta$-catenin and adopt the cell fate of the vegetal sister cell. This $\beta$-catenin asymmetry between sister cells from animal-vegetal cell divisions is reiterative and continues to specify cell fates until at least 12hpf (Schneider and Bowerman, 2007). In the canonical Wnt/ $\beta$-catenin signaling pathway, the binding of a Wnt ligand to its receptors causes a stabilization of cytoplasmic $\beta$-catenin and allows $\beta$-catenin to move to the nucleus to begin transcription of Wnt target genes. As this is a well-studied pathway, and there is a clear stabilization of $\beta$-catenin in the nuclei of vegetal pole sister cells in Platynereis, the identification of candidate wnt genes involved in the binary specification mediated by $\beta$-catenin was an important next step. If a wnt gene was involved in $\beta$-catenin-mediated binary specification, one could expect it to be ubiquitously expressed, localized symmetrically along the animal-vegetal axis, or expressed in a distinct pattern reminiscent of the $\beta$-catenin activation pattern, maybe expressed in the animal pole sister cells to signal to the vegetal pole sister cells.

To test the involvement of the twelve wnt ligands present in the Platynereis genome (Janssen et al., 2010) in the $\beta$-cateninmediated binary cell fate specification, the temporal and spatial expression patterns of the wnt ligands were examined. Temporal expression of the wnt complement through transcriptome analysis of early Platynereis development revealed a lack of significant maternal contribution by any wnt ligand (Fig. 2). Additionally, the transcriptome analysis established that few wnt ligands are expressed during early development ( $w n t A, w n t 4, w n t 5$, and wnt8), but these wnts are not expressed during the early spiral cleavage stage (Fig. 2). WMISH confirmed the temporal expression pattern of the wnt ligands (Fig. 3-5), and that the zygotic expression begins primarily in cell lineages on the dorsal side, which does not explain the $\beta$-catenin asymmetries in the ventral cell lineages. Together, the temporal and spatial expression patterns suggest a wnt-independent mechanism for the binary specification through $\beta$-catenin. Another possibility is that very low transcript levels of a wht ligand, below the RNA-Seq and in situ detection level, like $w n t 8$, could be sufficient to trigger early $\beta$-catenin activation. Further analysis by loss-of-function experiments is necessary to exclude this possibility.

The likely wnt-independent mechanism for the binary specification through $\beta$-catenin in Platynereis might be in contrast to what is seen in the nematode $C$. elegans. $C$. elegans is another species that exhibits $\beta$-catenin activation asymmetries throughout early development. In $C$. elegans, most divisions that take place along the anterior-posterior axis show asymmetric activation of $\beta$-catenin, with high levels of $\beta$-catenin in the posterior sister cell (Park and Priess, 2003), and part of the asymmetry is due to Wnt signaling. At the 4-cell stage, MOM-2/Wnt signals from a cell, $\mathrm{P}_{2}$, to the adjacent cell, EMS. EMS will divide along the anterior-posterior axis to become the anterior MS cell (mesoderm precursor) and the posterior $E$ cell (endoderm precursor). The Wnt signal from $\mathrm{P}_{2}$ is essential for $\beta$-catenin activation in the posterior cell, E. Asymmetries up to the $A B^{8}$ stage in $C$. elegans are regulated, at least in part, by MOM-2Nnt signaling. Cell divisions after $A B^{16}$ seem to be independent of Wnt signaling and require MOM-5/Frizzled instead (Park and Priess, 2003).

\section{Wnt signaling centers in early Platynereis development}

Although the extensive $\beta$-catenin-mediated binary cell fate specification mechanism may act independently of the wnts, some wnt ligands are expressed in specific subsets of cells during early Platynereis development. These 'early' wnts are first expressed

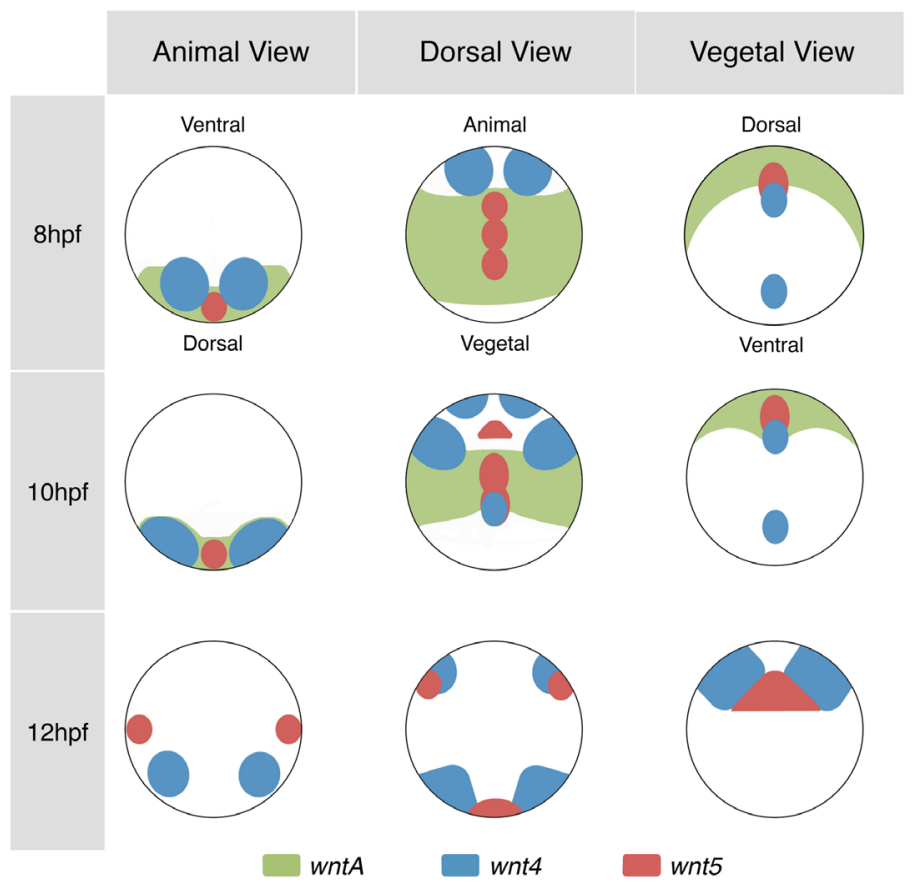

Fig. 7. Interpretive illustration for early wnt gene expression in Platynereis dumerilii. The schematics depict the hypothesized overlap of wntA, wnt4, and wnt5a in 8, 10, and 12hpf embryos. wntA is shown in green, wnt4 is shown in blue, and wnt5a in red. The orientations of the schematics are the same as Fig. 3-5. wntA, wnt4, and wnt5a are predominantly expressed in dorsal cell lineages and absent on the ventral side of the embryos. 
at the transition to bilateral symmetrical cleavages after 6hpf and are initially confined to dorsal cell lineages. As the 'early' wnts are expressed in dorsal midline cells and/or in a bilateral symmetrical pattern on the dorsal side of the embryo (Fig. 7), these wnts may function as early wnt signaling centers and organizers to pattern the dorsal-ventral axis.

$w n t A$ is the first $w n t$ ligand expressed with a distinct expression pattern. At $6 \mathrm{hpf}, w n t A$ is expressed in $2 \mathrm{~d}^{1}$. wht $A$ expression increases during the next two hours of development, with the peak expression at $8 \mathrm{hpf}$ (Fig. 2). $2 \mathrm{~d}^{1}$ is a dominant cell lineage involved in establishing bilateral symmetry and dorsal-ventral axial tissues in the trunk ectoderm, and could act as a potential dorsal trunk organizer in Platynereis. $2 \mathrm{~d}^{1}$ is one of the progeny from the somatoblast $2 \mathrm{~d}$, that is the sole progenitor of the trunk ectoderm, and one progeny of $2 \mathrm{~d}^{1}, 2 \mathrm{~d}^{112}$, is one of the first cells in Platynereis to divide with bilateral symmetry. It is possible that $2 \mathrm{~d}^{1}$ could act as a signaling center to coordinate bilateral symmetry in the dorsal trunk. Interestingly, in another polychaete annelid Capitella teleta, the somatoblast $2 \mathrm{~d}$ acts as a signaling center and is required for bilateral symmetry and dorsal-ventral axial tissue organization (Amiel et al., 2013). Single-cell laser ablation was used in Capitella to determine whether or not a cell had organizing activity, and this type of experiment would be needed to determine if $2 \mathrm{~d}^{1}$ is indeed a dorsal trunk organizer in Platynereis embryos. However, the observed localization pattern makes wntA a prime candidate to convey dorsal organizing activity to the $2 \mathrm{~d}$ cell lineage in both species.

Wnt signaling centers in the animal hemisphere and along the dorsal midline could be elicited by wnt4 and wnt5, respectively. The earliest expression of wnt 4 is confined to two bilateral symmetrical expression domains in the anterior, and additional cells along the dorsal midline. Early wnt4 localization (most likely descendants of $1 \mathrm{c}^{112}$ and $1 \mathrm{~d}^{112}$ ) is the most anterior expression of any of the 'early' wnts, and the cells with early wnt4 expression will form dorsal tissues within the animal hemisphere of the trochophore larvae. Therefore, wnt4 may convey dorsal organizing property within the head region. wnt5 is expressed first at 8 hpf in $\sim 4$ cells. Three of the four wnt5 expressing cells are forming the dorsal midline, and three cells continue to express wht5 in this region until 10hpf (Fig. 5 and Fig. 7). Thus, wnt5 may have important functions to define and maintain the dorsal midline and adjacent dorsal tissues.

In total, the combination of early wntexpression delineates most major dorsal cell lineages (Fig. 7). It is possible that the 'early' wnts act as dorsal signaling centers and are involved in patterning the dorsal-ventral axis.

\section{Wnt signaling during early development in other species}

Wnt signaling during early development has been directly or indirectly implicated in cell fate specification in other species. The expression of the 13 wnt genes (representing 9 wnt subfamilies) has been studied in the leech Helobdella robusta. In Helobdella, there is extensive overlap of wnt expression during the spiral cleavage stage, and most wnts are expressed in cells that will give rise to the mesoderm and ectoderm (Cho et al., 2010). In other spiralians, like the nemertean Cerebratulus lacteus and the gastropod Crepidula fornicata, the expression patterns of wnt ligands has not been determined, but the localization of $\beta$-catenin has been studied. In Cerebratulus lacteus, $\beta$-catenin is specifically localized to the nuclei of the vegetal-most cells at the 64-cell stage that give rise to the endoderm, suggesting that $\beta$-catenin is required for endoderm formation in Cerebratulus (Henry et al., 2008). In Crepidula fornicata, $\beta$-catenin is stabilized in the progeny of the mesentoblast, the progenitor of the endomesoderm (Henry et al., 2010). Thus, the currently limited knowledge of wnt expression and $\beta$-catenin function in early spiral-cleaving embryos including Platynereis provides only little evidence for common conserved mechanisms, and may point to a divergence of wnt-related mechanisms among spiralians.

Early wntsignaling has been observed in a wide variety of species like $C$. elegans, sea urchins, and frogs (for review, see (Petersen and Reddien, 2009; Schneider and Bowerman, 2007)). Similar to Platynereis, $\beta$-catenin has a binary mode of specification during early $C$. elegans development. In divisions taking place along the anterior-posterior axis, those posterior sister cells have high levels of SYS-1/ $\beta$-catenin, and Wnt signaling via LIN-17/Frizzled is required in the posterior cells for SYS-1/ $\beta$-catenin and POP-1/ TCF mediated activation of target genes (Kidd et al., 2005). In sea urchin, the wnt signaling pathway is involved in the specification of the animal-vegetal axis. The maternally provided $\beta$-catenin moves into the nuclei of the vegetal cells and there it functions to specify the skeletogenic fates of the micromeres and the endomesoderm fates of the macromeres (Logan et al., 1999). The maternally provided wnt6 and wnt receptor frizzled 1/2/7 are required for endoderm specification (Croce et al., 2011; Lhomond et al., 2012). In Xenopus, the wnt pathway is involved in the specification of the dorsal-ventral axis. The maternally provided wnt 11 is required for the nuclear localization of $\beta$-catenin on the future dorsal side of the embryo (Tao et al., 2005). In Platynereis, wnt6 and wnt11 are not maternally provided, nor are they expressed during early development until at least late gastrula stages ( $\sim 330$ cells). Thus, although maternal contribution of wnt ligands and wnt-dependent $\beta$-catenin-mediated mechanisms to specify early embryonic cell fates appear to be widespread among various species, there are no apparent similarities in the type of wnt ligands that triggers $W n t / \beta$-catenin-mediated cell fate specification mechanism in early embryos between Platynereis and other species.

\section{A posterior bias: wnt signaling in Platynereis trochophore larvae}

To determine potential wntsignaling centers in later development of Platynereis, the expression patterns of the wntcomplement were investigated in early and late trochophore larvae. Plotting relative expression levels and positions of all 12 wnts along the anteriorposterior axis (Fig. 8) reveals three subdivisions in early and late trochophore larva: 1) anterior to the prototroch, 2) the prototroch, and 3) posterior to the prototroch.

1) Wnt signaling centers anterior to the prototroch. Only 6 of the $12 w n t$ ligands are expressed anterior to the prototroch in the developing brain, $w n t A$, wnt11, wnt8, wnt5, wnt4 and wnt2. This is an interesting group of wnt ligands as half of those, wntA, wnt4, and $w n t 5$, are the wnt ligands with early expression patterns, part of which were expressed in progenitor cells of the anterior/episphere cell lineages including lineages that give rise to the developing brain. This is an intriguing observation as this could mean that a wnt gene that is expressed earlier in the progenitor cells can more easily function later within the same cell lineage or that a wnt gene that has assumed a role in later development can be more easily redeployed in earlier roles in progenitor cells. The wnt ligands that are expressed anterior to the prototroch appear to act as a 
lateral signaling center to pattern the developing brain, and these results are consistent with another publication studying conserved patterning mechanisms between vertebrates and annelids (Tomer et al., 2010). The expression of the wnt ligands in the developing brain is excluded from the most anterior region, and is mostly expressed in lateral regions (Supplementary Figs. 2,3). Vertebrates also have wnt signaling centers in the developing brain, however in vertebrates, the signaling center is from the dorsal side as opposed to the lateral signaling center seen in Platynereis (Danesin et al., 2009). In both vertebrates and Platynereis, there are two opposing signaling centers in the brain, hedgehog signaling and wnt signaling. In vertebrates, hedgehog signaling comes from the ventral side and wnt signaling comes from the dorsal side. In

A

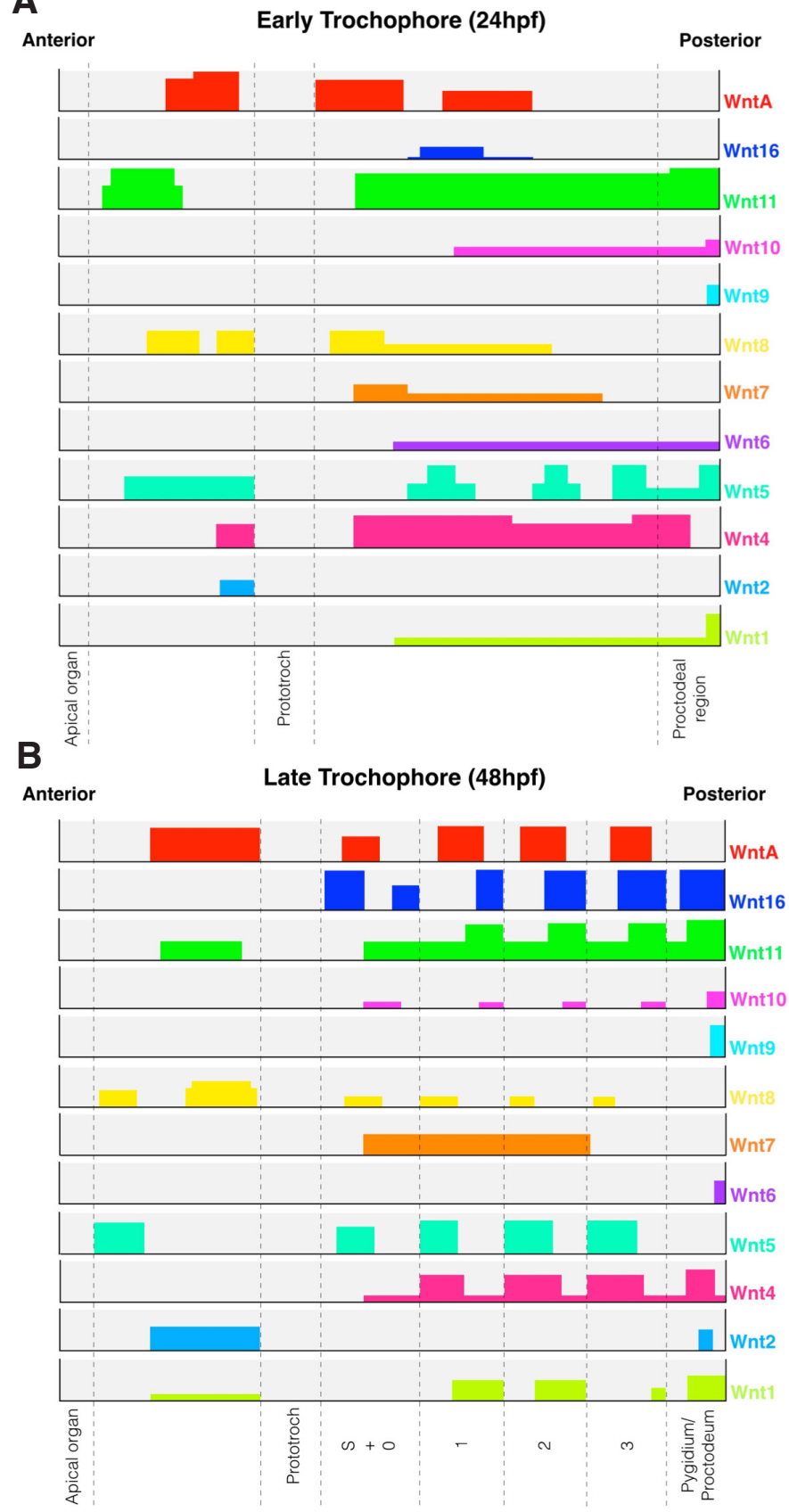

Platynereis, hedgehog signaling comes from a medial location, and wnt signaling from a more lateral location (Tomer et al., 2010).

2) A lack of Wnt signaling centers at the prototroch. At both $24 \mathrm{hpf}$ and $48 \mathrm{hpf}$, there is a lack of wnt expression in the prototroch. The ciliated cells of the prototroch are the first cells to terminally differentiate in Platynereis embryos, and it is interesting that these differentiating cells do not express any of the $12 \mathrm{wnt}$ ligands, and separate two major larval domains that harbor potentially active wnt signaling centers.

3) Wnt signaling posterior to the prototroch. Most significantly, all of the wnt ligands in Platynereis are expressed in staggered domains with a bias to the posterior at 24hpf and 48hpf with the exception of wht2 at $24 \mathrm{hpf}$ (Fig. 8). At both $24 \mathrm{hpf}$ and $48 \mathrm{hpf}$ in Platynereis, the entire trunk region from posterior to the prototroch to the pygidium has the expression of at least one wnt gene. The expression domains of the different wnts have a clear staggered appearance, and a number of wnts are also expressed in segmental patterns. The earliest segmental pattern detected was wnt5 at 24hpf (Fig. 6 and Fig. 8). Later, at 48hpf, wnt1, wnt4, wnt5, wnt8, wnt10, wnt11, and wnt16 have segmental expression domains. The segmental expression domains at $48 \mathrm{hpf}$ are consistent with previous work on 48hpf larvae and juvenile worms studying the role of the wnt ligands in segmentation and the posterior growth zone (Janssen et al., 2010). The segmental expression domains seen in Platynereis are also seen in other animals, like the two annelids Helobdella and Capitella (Cho et al., 2010). While segmental expression domains for wnts are seen in a number of animals, it is even more common to see a staggered wnt expression pattern in the posterior of numerous animal species (Holland, 2002; Kusserow et al., 2005; Lee et al., 2006; Lengfeld et al., 2009; Petersen and Reddien, 2009).

Polarized expression of wnts and/or $\beta$-catenin are seen in a number of different metazoans from deuterostomes to protostomes to pre-bilaterians, but the expression of wnts and/or nuclear $\beta$ catenin is most commonly biased towards the posterior (Petersen and Reddien, 2009). In contrast to the work presented by Petersen and Reddien (Petersen and Reddien, 2009) who point out posterior signaling centers based on the expression of a few wnt genes and $\beta$-catenin activation, Platynereis exhibits a posterior bias in the expression for all wnt genes. This is a significant difference as this feature is very similar to observation of wnt expression in the cnidarians Nematostella vectensis and Hydra magnipapillata. Nematostella does not have an anterior-posterior axis but instead an oral-aboral axis, and in Nematostella there is a bias for all wnt genes to be expressed at the oral end (Kusserow et al., 2005; Lee et al., 2006). While the oral is thought to be anterior and the bias is in the opposite orientation as Platynereis, the expression of the

Fig. 8. Schematic illustration of wnt expression domains in early and late trochophore larva. Anterior is to the left and posterior is to the right. Relative heights of the bars represent higher and lower expression levels. The placement of the bars refers to wnt expression along the anterior (apical organ) to posterior axis (pygidium/proctodeum), and is based on WMISH data analyzed from Fig. 6, Sup. Fig. 2, and Sup. Fig. 3. The location of the apical organ, prototroch, and proctodeal region are indicated in (A) $24 \mathrm{hpf}$, and the location of the apical organ, prototroch, stomodeum (S), the transient segment 0 , larval segments 1, 2, and 3, and the pygidium/proctodeum are indicated in (B) 48hpf. See Fig. $1 \mathrm{C}$ for schematics of these structural features. These plots show the strong bias for posterior expression of the wnt complement in Platynereis in both early and late trochophore larva. 
complete wnt gene complement is polarized across the oral-aboral axis and is expressed in staggered domains, similar to Platynereis. The Hydra genome contains 8 of the 13 wnt subfamilies, and 6 of the wnt subfamilies have expression in the adult hypostome (apical half of the head) and act there as a wnt signaling center, a head organizer (Lengfeld et al., 2009). It is interesting that there are similar, polarized signaling centers expressing multiple wnts in animals as different as Platynereis, Nematostella, Hydra, and deuterostomes like Xenopus and Amphioxus, an observation that was drawn attention to by Holland and others (Holland, 2002). The data presented here, and previous data from many other labs, points to biased signaling centers towards a major body axis with staggered wntexpression domains as an evolutionarily conserved feature. These biased staggered wnt domains may function in cell fate specification and axis formation, and might have been exploited during animal evolution to establish novel features like segmentation along the anterior-posterior axis.

In Nematostella, wnts are expressed around the blastopore (Kusserow et al., 2005; Lee et al., 2006); in Hydra, the wnts are expressed in the hypostome (Lengfeld et al., 2009); in Platynereis and arthropods, wnts are expressed in the posterior growth zones (Janssen et al., 2010). whts are also expressed in the tail organizer in frog, fish, and amphioxus (Holland, 2002). While these may seem like different structures, they might be all related to the blastopore as suggested previously by Haeckel and elaborated by others (see Supplementary References). Perhaps the polarized wnt expression domains observed in extant species are a legacy of the common cnidarian/bilaterian ancestor, and share a common evolutionary origin that relate the body plans from cnidarians to annelids and vertebrates.

\section{Materials and Methods}

\section{Animal culture}

Platynereis dumeriliicultures were maintained using established procedures (www. platynereis.de) (Fischer and Dorresteijn, 2004). Synchronously developing embryos and larvae were kept at $18^{\circ} \mathrm{C}$ until the time of fixation. Prior to fixation, embryos younger than $14 \mathrm{hpf}$ were treated twice for $3 \mathrm{~min}$ in $25 \mathrm{~mL}$ TCMFSW (50mM Tris, $495 \mathrm{mM} \mathrm{NaCl}, 9.6 \mathrm{mM} \mathrm{KCl}, 27.6 \mathrm{mM} \mathrm{Na}_{2} \mathrm{SO}_{4}$, 2.3mM NaHCO, $6.4 \mathrm{mM}$ EDTA [pH 8.0]) to remove the eggshell (Schneider and Bowerman, 2007). Embryos and larvae were transferred to fixative (4\% paraformaldehyde, 0.1M MOPS, $2 \mathrm{mM}$ EGTA, $1 \mathrm{mM} \mathrm{MgSO}_{4}, 0.1 \%$ Tween20) and fixed overnight at $4^{\circ} \mathrm{C}$ on a nutator. After fixation, embryos and larvae were washed in phosphate-buffered saline with $0.1 \%$ Tween20 and stored in methanol at $-20^{\circ} \mathrm{C}$.

\section{Transcriptional profiling using RNA-Seq}

Total RNA was extracted from batches of synchronously developing embryos in Trizol (Ambion) according to manufacturer's instruction. Extracted RNA was treated with the RNase-free DNase Set (QIAGEN) and purified using an RNeasy Mini Kit (QIAGEN). The total RNA was extracted from seven embryonic stages in two-hour intervals, from $2 \mathrm{hpf}-14 \mathrm{hpf}$, with biological replicates. For four embryonic stages (4hpf, 6hpf, $8 \mathrm{hpf}$ and $14 \mathrm{hpf}$ ), including biological replicates, additional technical replicates were generated. For all the expressed coding genes, the correlation coefficient (using Spearman method) for the biological and technical replicates is 0.93 and 0.99 respectively, showing good reproducibility of these replicates. mRNAdeep-sequencing was performed with $75 \mathrm{bp}-100 \mathrm{bp}$ paired-end reads using an Illumina HiSeq sequencing system at the IGSP at Duke University. A total of 2.1 billion reads were sequenced. Trimmomatic (Lohse et al., 2012) was used to remove the adaptor sequences and the low quality regions. Around $93 \%$ of the reads remained after the pre-processing and were mapped to the gene models using Bowtie1.0 aligner (Langmead et al., 2009). $88 \%$ of the filtered reads can be successfully mapped to the reference transcriptome. The read count of each sample was estimated by RSEM (Li et al., 2010), and the FPKM (fragments per kilobase per million mapped reads) was calculated by the normalization of the total mappable reads and the transcript length.

\section{Whole-mount In situ hybridization}

The wnt clones were provided by Guillaume Balavoine (IJM, Paris, France). RNA probes were synthesized with the DIG RNA labeling kit SP6/T7 (Roche), according to the manufacturer's protocol. WMISH was carried out using established protocols (Asadulina et al., 2012), with the following modifications: procedure was performed in $1.5 \mathrm{~mL}$ tubes until visualization of the probe, hybridization with the RNA probe occurred at $65^{\circ} \mathrm{C}$ for at least 40 hours (hybridization buffer: $50 \%$ formamide, 5X SSC, $50 \mu \mathrm{g} / \mathrm{mL}$ Heparin, $0.25 \%$ Tween $20,1 \%$ SDS, $0.2 \mathrm{mg} / \mathrm{mL}$ Salmon Sperm DNA), the alkaline phosphatase buffer did not contain polyvinyl alcohol, and embryos and larvae were stored in $87 \%$ glycerol at $4^{\circ} \mathrm{C}$. After WMISH, embryos were co-stained with DAPI to aid in cell identification and number of wnt expressing cells. At least 100 embryos were analyzed per stage and the combined stereotypic patterns of expression are reported here. Images were taken on an LSM700 Microscope with an AxioCam MRc5 camera, and adjusted in Adobe Photoshop.

\section{Note added in proof}

In the Results section Spatial expression in early (24hpf) and late (48hpf) trochophore larvae, it is stated that the expression patterns for the wnt ligands have only been reported for late trochophore larvae in Platynereis. While this manuscript was under revision, Marlow and colleagues published a paper with a description of wnt 4 expression at $16 \mathrm{hpf}$ and 20hpf in Platynereis (Marlow et al., 2014). While 16hpf and 20hpf embryos were not used in this study, the expression pattern is similar to what is shown here at $24 \mathrm{hpf}$.

\section{Acknowledgements}

We would like to thank Guillaume Balavoine for generously sharing all of the wnt clones. We would also like to thank the two anonymous reviewers for comments on the manuscript. Funding for this work came from the Roy J. Carver Charitable Trust and the Center for Integrated Animal Genomics.

\section{References}

AMIEL, AR, HENRY, J Q and SEAVER, E C. (2013). An organizing activity is required for head patterning and cell fate specification in the polychaete annelid Capitella teleta: New insights into cell-cell signaling in Lophotrochozoa. Dev Biol379: 107-122.

ASADULINA, A, PANZERA, A, VERASZTÓ, C, LIEBIG, C and JÉKELY, G. (2012). Whole-body gene expression pattern registration in Platynereis larvae. EvoDevo 3: 27.

CHO, S J, VALLES, Y, GIANI, V C, SEAVER, E C and WEISBLAT, D A. (2010) Evolutionary Dynamics of the wnt Gene Family: A Lophotrochozoan Perspective. Mol Biol Evol 27: 1645-1658.

CROCE, J, RANGE, R, WU, S Y, MIRANDA, E, LHOMOND, G, PENG, J C F, LEPAGE, T and MCCLAY, D R. (2011). Wnt6 activates endoderm in the sea urchin gene regulatory network. Development 138: 3297-3306.

CROCE, J C, WU, S-Y, BYRUM, C, XU, R, DULOQUIN, L, WIKRAMANAYAKE, A H, GACHE, C and MCCLAY, D R. (2006). A genome-wide survey of the evolutionarily conserved Wnt pathways in the sea urchin Strongylocentrotus purpuratus. Dev Biol 300: 121-131.

DANESIN, C, PERES, J N, JOHANSSON, M, SNOWDEN, V, CORDING, A, PAPALOPULU, N and HOUART, C. (2009). Integration of Telencephalic Wnt and Hedgehog Signaling Center Activities by Foxg1. Dev Cell 16: 576-587.

DORRESTEIJN, A. (1990). Quantitative analysis of cellular differentiation during early embryogenesis of Platynereis dumerilii. Roux Arch Dev Biol 199: 14-30.

FISCHER, A and DORRESTEIJN, A. (2004). The polychaete Platynereis dumerili (Annelida): a laboratory animal with spiralian cleavage, lifelong segment prolifera- 
tion and a mixed benthic/pelagic life cycle. BioEssays 26: 314-325.

FISCHER, A H, HENRICH, T and ARENDT, D. (2010). The normal development of Platynereis dumerilii (Nereididae, Annelida). Front Zool 7: 31.

GARRIOCK, R J, WARKMAN, A S, MEADOWS, S M, D'AGOSTINO, S and KRIEG, P A. (2007). Census of vertebrate Wnt genes: Isolation and developmental expression of Xenopus Wnt2, Wnt3, Wnt9a, Wnt9b, Wnt10a, and Wnt16. Dev Dynam 236: 1249-1258.

HENRY, J Q, PERRY, K J and MARTINDALE, M Q. (2010). $\beta$-catenin and early development in the gastropod, Crepidula fornicata. ICB 50: 707-719.

HENRY, J Q, PERRY, K J, WEVER, J, SEAVER, E and MARTINDALE, M Q. (2008). Beta-catenin is required for the establishment of vegetal embryonic fates in the nemertean, Cerebratulus lacteus. Dev Biol 317: 368-379.

HOLLAND, L Z. (2002). Heads or Tails? Amphioxus and the Evolution of AnteriorPosterior Patterning in Deuterostomes. Dev Biol 241: 209-228.

JANSSEN, R, LE GOUAR, M, PECHMANN, M, POULIN, F, BOLOGNESI, R, SCHWAGER, E E, HOPFEN, C, COLBOURNE, J K, BUDD, G E, BROWN, S J et al., (2010). Conservation, loss, and redeployment of Wnt ligands in protostomes: implications for understanding the evolution of segment formation. BMC Evol Biol 10: 374.

KIDD, I, AMBROSE R, MISKOWSKI, J A, SIEGFRIED, K R, SAWA, H and KIMBLE, J. (2005). A $\beta$-Catenin Identified by Functional Rather Than Sequence Criteria and Its Role in Wnt/MAPK Signaling. Cell 121: 761-772.

KUSSEROW, A, PANG, K, STURM, C, HROUDA, M, LENTFER, J, SCHMIDT, H, TECHNAU, U, VON HAESELER, A, HOBMAYER, B, MARTINDALE, M $Q$ et al., (2005). Unexpected complexity of the Wnt gene family in a sea anemone. Nature 433: 156-160.

LANGMEAD, B, TRAPNELL, C, POP, M and SALZBERG, S L. (2009). Ultrafast and memory-efficient alignment of short DNA sequences to the human genome. Genome Biol 10: R25.

LEE, P, PANG, K, MATUS, D and MARTINDALE, M. (2006). A WNT of things to come: Evolution of Wnt signaling and polarity in cnidarians. Semin Cell Dev Biol 17: 157-167.

LENGFELD, T, WATANABE, H, SIMAKOV, O, LINDGENS, D, GEE, L, LAW, L, SCHMIDT, HA, ÖZBEK, S, BODE, H and HOLSTEIN, TW. (2009). Multiple Wnts are involved in Hydra organizer formation and regeneration. Dev Bio/330: 186-199.
LHOMOND, G, MCCLAY, D R, GACHE, C and CROCE, J C. (2012). Frizzled1/2/7 signaling directs $\beta$-catenin nuclearisation and initiates endoderm specification in macromeres during sea urchin embryogenesis. Development 139: 816-825.

LI, B, RUOTTI, V, STEWART, R M, THOMSON, J A and DEWEY, C N. (2010). RNASeq gene expression estimation with read mapping uncertainty. Bioinformatics 26: 493-500.

LOGAN, C Y, MILLER, J R, FERKOWICZ, M J and MCCLAY, D R. (1999). Nuclear beta-catenin is required to specify vegetal cell fates in the sea urchin embryo. Development 126: 345-357.

LOGAN, C Y and NUSSE, R. (2004). The Wnt signaling pathway in development and disease. Annu Rev Cell Dev Biol 20: 781-810.

LOHSE, M, BOLGER, A M, NAGEL, A, FERNIE, A R, LUNN, J E, STITT, M and USADEL, B. (2012). RobiNA: a user-friendly, integrated software solution for RNA-Seq-based transcriptomics. Nucleic Acids Res 40: W622-W627.

MARLOW, H, TOSCHES, MA, TOMER, R, STEINMETZ, PR, LAURI, A, LARSSON, T and ARENDT, D. (2014). Larval body patterning and apical organs are conserved in animal evolution. BMC biology 12: 7.

PARK, F D and PRIESS, J R. (2003). Establishment of POP-1 asymmetry in early C. elegans embryos. Development 130: 3547-3556.

PETERSEN, C P and REDDIEN, P W. (2009). Wnt Signaling and the Polarity of the Primary Body Axis. Cell 139: 1056-1068.

RUVKUN, G and HOBERT, O. (1998). The Taxonomy of Developmental Control in Caenorhabditis elegans. Science 282: 2033-2041.

SCHNEIDER, S Q and BOWERMAN, B. (2007). $\beta$-Catenin Asymmetries after All Animal/Vegetal- Oriented Cell Divisions in Platynereis dumerilii Embryos Mediate Binary Cell-Fate Specification. Dev Cell 13: 73-86.

TAO, Q, YOKOTA, C, PUCK, H, KOFRON, M, BIRSOY, B, YAN, D, ASASHIMA, M, WYLIE, C C, LIN, X and HEASMAN, J. (2005). Maternal Wnt11 Activates the Canonical Wnt Signaling Pathway Required for Axis Formation in Xenopus Embryos. Cell 120: 857-871.

TOMER, R, DENES, A S, TESSMAR-RAIBLE, K and ARENDT, D. (2010). Profiling by Image Registration Reveals Common Origin of Annelid Mushroom Bodies and Vertebrate Pallium. Cell 142: 800-809. 


\section{Further Related Reading, published previously in the Int. J. Dev. Biol.}

Brachyury, Tbx2/3 and sall expression during embryogenesis of the indirectly developing polychaete Hydroides elegans Cesar Arenas-Mena

Int. J. Dev. Biol. (2013) 57: 73-83

http://dx.doi.org/10.1387/ijdb.120056ca

Stable expression of Y-box protein 1 gene in early development of the abalone Haliotis diversicolor Jun Chen, Zhi-Sen Chen, Zi-Xia Huang, Cai-Huan Ke, Jie Zhang, Yi-Xiang Zhong, Wei-Wei You and Jing Zhao Int. J. Dev. Biol. (2012) 56: 369-375

http://dx.doi.org/10.1387/ijdb.113487zc

Functional analysis of grimp, a novel gene required for mesodermal cell proliferation at an initial stage of regeneration in Enchytraeus japonensis (Enchytraeidae, Oligochaete)

Makoto Takeo, Chikako Yoshida-Noro and Shin Tochinai

Int. J. Dev. Biol. (2010) 54: 151-160

http://dx.doi.org/10.1387/ijdb.082790mt

Hox and ParaHox genes in Nemertodermatida, a basal bilaterian clade

Eva Jiménez-Guri, Jordi Paps, Jordi García-Fernández and Emili Saló

Int. J. Dev. Biol. (2006) 50: 675-679

http://dx.doi.org/10.1387/ijdb.062167ej

On the origin of pattern and form in early Metazoans

Frederick W. Cummings

Int. J. Dev. Biol. (2006) 50: 193-208

http://dx.doi.org/10.1387/ijdb.052058fc

Segmentation: mono- or polyphyletic?

Elaine C Seaver

Int. J. Dev. Biol. (2003) 47: 583-595

http://dx.doi.org/10.1387/ijdb.14756334

Ecological regulation of development: induction of marine invertebrate metamorphosis Daniel Jackson, Sally P Leys, Veronica F Hinman, Rick Woods, Martin F Lavin and Bernard M Degnan

Int. J. Dev. Biol. (2002) 46: 679-686

http://dx.doi.org/10.1387/ijdb.12141457

5 yr ISI Impact Factor $(2011)=2.959$
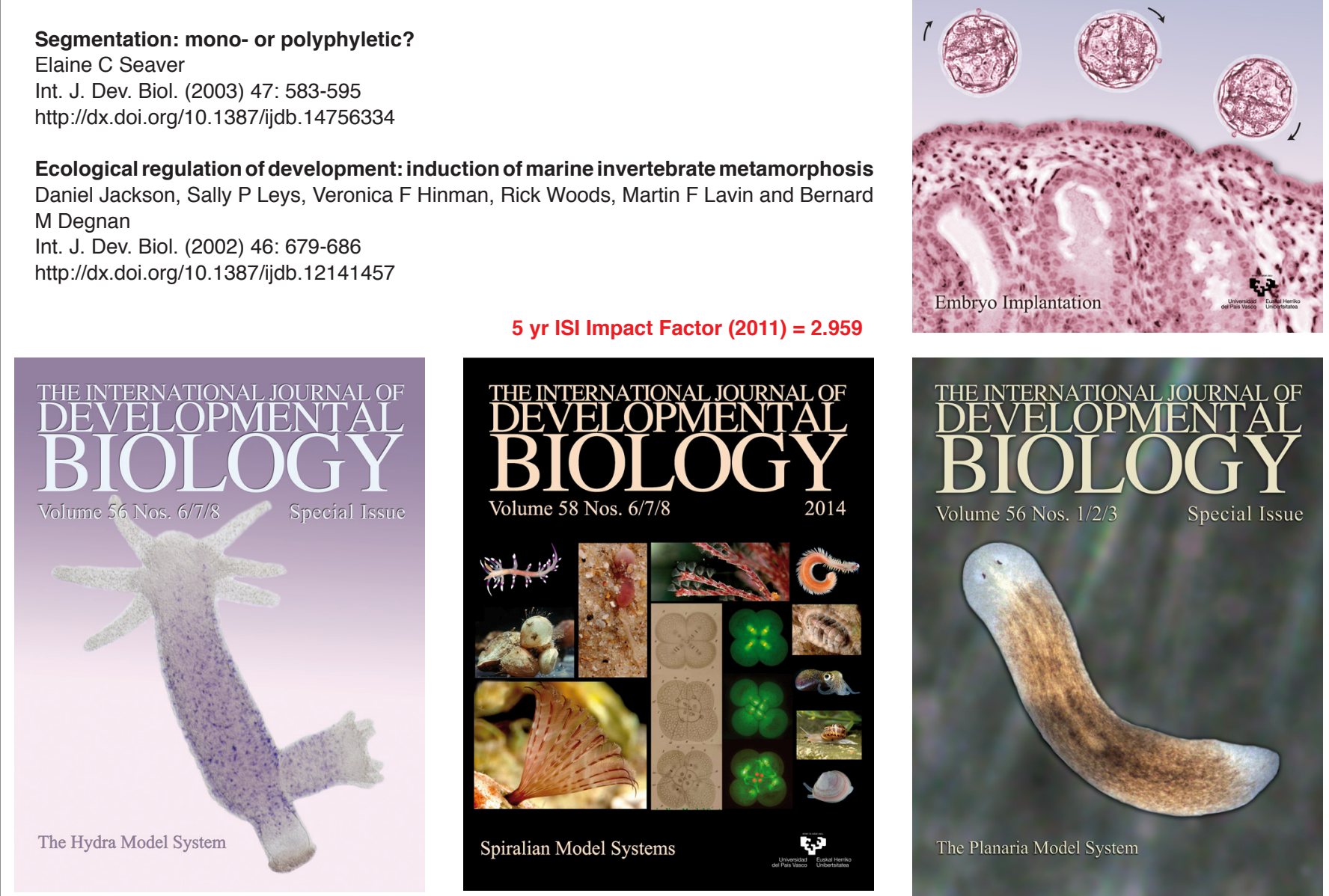

Spiralian Model Systems
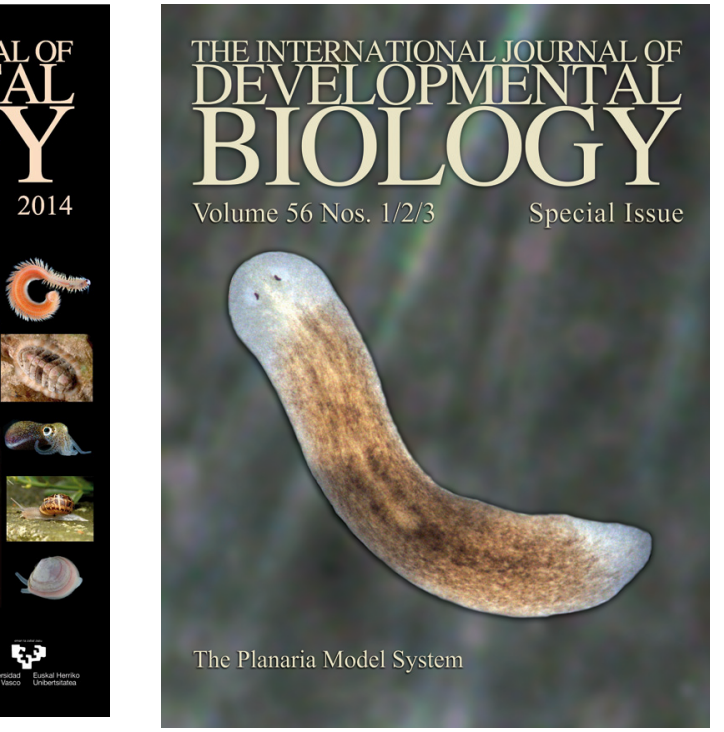